\title{
Protective effect of geranylgeranylacetone, an inducer of heat shock protein 70, against drug-induced lung injury/fibrosis in an animal
} model

\author{
Takayoshi Fujibayashi $^{\dagger 1}$, Naozumi Hashimoto ${ }^{\dagger 2}$, Mayumi Jijiwa3, \\ Yoshinori Hasegawa2 ${ }^{2}$ Toshihisa Kojima*1 and Naoki Ishiguro ${ }^{1}$
}

Address: ${ }^{1}$ Department of Orthopedic Surgery, Nagoya University Graduate School of Medicine, Nagoya, Japan, ${ }^{2}$ Department of Respiratory Medicine, Nagoya University Graduate School of Medicine, Nagoya, Japan and ${ }^{3}$ Department of Pathology, Nagoya University Graduate School of Medicine, Nagoya, Japan

Email: Takayoshi Fujibayashi - takafuji@med.nagoya-u.ac.jp; Naozumi Hashimoto - hashinao@med.nagoya-u.ac.jp;

Mayumi Jijiwa - j2w@med.nagoya-u.ac.jp; Yoshinori Hasegawa - yhasega@med.nagoya-u.ac.jp;

Toshihisa Kojima* - toshik@med.nagoya-u.ac.jp; Naoki Ishiguro - n-ishi@med.nagoya-u.ac.jp

* Corresponding author †Equal contributors

Published: 16 September 2009

BMC Pulmonary Medicine 2009, 9:45 doi:10.1 I86/1471-2466-9-45

This article is available from: http://www.biomedcentral.com/I47/-2466/9/45

(c) 2009 Fujibayashi et al; licensee BioMed Central Ltd.

This is an Open Access article distributed under the terms of the Creative Commons Attribution License (http://creativecommons.org/licenses/by/2.0), which permits unrestricted use, distribution, and reproduction in any medium, provided the original work is properly cited.
Received: 30 December 2008

Accepted: 16 September 2009

\begin{abstract}
Background: To determine whether oral administration of geranylgeranylacetone (GGA), a nontoxic anti-ulcer drug that is an inducer of heat shock protein (HSP) 70 , protects against druginduced lung injury/fibrosis in vivo.

Methods: We used a bleomycin (BLM)-induced lung fibrosis model in which mice were treated with oral $600 \mathrm{mg} / \mathrm{kg}$ of GGA before and after BLM administration. Inflammation and fibrosis were evaluated by histological scoring, hydroxyproline content in the lung and inflammatory cell count, and quantification by ELISA of macrophage inflammatory protein-2 (MIP-2) in bronchoalveolar lavage fluid. Apoptosis was evaluated by the TUNEL method. The induction of HSP70 in the lung was examined with western blot analysis and its localization was determined by immunohistochemistry.
\end{abstract}

Results: We confirmed the presence of inflammation and fibrosis in the BLM-induced lung injury model and induction of HSP70 by oral administration of GGA. GGA prevented apoptosis of cellular constituents of lung tissue, such as epithelial cells, most likely related to the de novo induction of HSP70 in the lungs. GGA-treated mice also showed less fibrosis of the lungs, associated with the findings of suppression of both production of MIP-2 and inflammatory cell accumulation in the injured lung, compared with vehicle-treated mice.

Conclusion: GGA had a protective effect on drug-induced lung injury/fibrosis. Disease-modifying antirheumatic drugs such as methotrexate, which are indispensable for the treatment of rheumatoid arthritis, often cause interstitial lung diseases, an adverse event that currently cannot be prevented. Clinical use of GGA for drug-induced pulmonary fibrosis might be considered in the future. 


\section{Background}

Rheumatoid arthritis (RA), a chronic, systemic, inflammatory autoimmune disease, causes irreversible joint deformities and functional impairment. Evidence accumulating over the past 10 years has suggested that combined treatment with disease-modifying antirheumatic drugs (DMARDs), especially methotrexate, and anti-TNFa biological agents, as early as possible after the diagnosis of RA is effective and critical for preventing substantial disability caused by bony erosions [1-4]. On the other hand, it is also well known that DMARDs and other drugs for RA have various adverse effects, which require discontinuation or revision of the therapeutic schedule $[5,6]$. Since drug-induced interstitial pneumonitis is a well-known complication among these adverse effects that is often life-threatening [7-9], investigation for preventing its onset during the treatment for RA is warranted. Although the mechanism by which DMARDs cause interstitial pneumonitis remains unclear, clinical and histopathological evaluations suggest that it shares many features with idiopathic interstitial pneumonitis (IIP) [10,11], allowing us to speculate that the underlying mechanisms in the pathogenesis of IIP might be also involved in those in drug-induced interstitial pneumonia.

Although the pathological roles of cell injury and apoptosis in the epithelium of the airways during acute lung injury and fibrosis have not been fully determined, increased apoptosis of alveolar epithelial cells (AECs) has been observed in IIP, not only in the fibrotic lesions, but also in histologically normal alveoli [12-15].

The heat-shock proteins (HSPs) have a cytoprotective property as intracellular chaperones, by which aberrantly folded or mutated proteins involved in various stressful conditions are repaired and, if necessary, degraded for cellular homeostasis $[16,17]$. A wide variety of stresses, such as ischemia and inflammation, induce an increase in the expression of HSPs, and HSP70 in particular has been proved to not only exhibit a cytoprotective function through anti-apoptosis processes against stress in vitro, but to also exert strong cytoprotection in the stomach, liver, and heart in vivo [18-21].

Geranylgeranylacetone (GGA), a nontoxic anti-ulcer drug, has been recently shown to induce HSPs, especially HSP70, in various animal disease models, which suggests that the administration of GGA would have a protective effect against several injury models and human disease [22-24]. One possible mechanism, by which GGA can exert the cytoprotection, was shown to be anti-apoptosis effect by the induction of HSP70 in renal injury model [25].

To our knowledge, however, the protective effect of GGA on drug-induced lung injury/fibrosis has not been evalu- ated, so we investigated whether it had a cytoprotective effect and inhibited the progression of inflammation and fibrosis in a bleomycin (BLM)-induced lung fibrosis model.

\section{Methods \\ Reagents}

Bleomycin was kindly provided by Nippon Kayaku Co., Ltd (Tokyo, Japan) and GGA was obtained from Eisai Co., Ltd (Tokyo, Japan).

\section{Animals}

C57BL/6J (B6) mice (7- to 8-week-old females) purchased from Chubu Kagaku Shinzai Co., Ltd (Nagoya, Japan) were randomly divided into treatment groups and given access to food and water ad libitum. The study was conducted with the approval of Nagoya University Animal Experimentation and Ethics Committee.

\section{Administration of GGA in naïve mice}

GGA was emulsified and prepared in 5\% gum arabic and $0.6 \%$ Tween 80 for every administration to ensure a fresh suspension. Naïve mice were given a single oral dose of GGA at $600 \mathrm{mg} / \mathrm{kg}$ or vehicle. At $0,8,24$ or 48 hours after the administration of GGA, the mice were exsanguinated by aortic perforation under pentobarbital sodium anesthesia. The lung tissues were thoroughly perfused with saline to remove blood from the vascular bed, as described before [26], and then samples were collected to evaluate the induced HSP70 expression.

Some mice were treated with the same dose of GGA at 24 hours after the first administration, and then the lung tissues were collected at 48 hours after the first dose.

\section{Fibrosis model}

Acute pulmonary injury and fibrosis was induced by tracheal BLM administration, as described before [27]. Briefly, BLM was suspended in sterile saline and B6 mice were treated with $2 \mathrm{U} / \mathrm{kg}$ of body weight (BW) or the same volume of sterile saline (BLM mice and saline mice, respectively). The day of BLM administration was designated as day 0 . To evaluate whether GGA could exert a protective effect against BLM-induced lung injury and fibrosis, we monitored $\mathrm{BW}$, the change of which is assumed to closely correlate with the severity of BLMinduced lung injury [27].

\section{Administration of GGA in mouse fibrosis model}

Mice were pretreated with single daily doses of GGA at $600 \mathrm{mg} / \mathrm{kg}$ for 7 days before BLM administration and then until the indicated time for collection of samples. They were assigned to 1) vehicle-treated BLM mice, 2) GGAtreated BLM mice, 3) vehicle-treated saline mice, and 4) GGA-treated saline mice, respectively. 


\section{Collection of tissue specimens}

On BLM days 1 and 3, lung tissues were collected from the treated mice for evaluation of HSP70 expression and TUNEL staining. On BLM day 7, some mice underwent bronchoalveolar lavage (BAL) [28]. On BLM day 14, lung tissues were collected for histological evaluation and hydroxyproline measurement.

\section{Western blotting analysis for HSP70 expression in vivo}

Western blotting analysis was performed with minor modification $[28,29]$. Briefly, the resected tissues were homogenized with six volumes of ice-cold tissue lysis buffer consisting of $50 \mathrm{mM}$ Tris base-pH 6.8, 2\% sodium dodecyl sulfate (SDS), $150 \mathrm{mM} \mathrm{NaCl}, 5 \mathrm{mM}$ ethylenediaminetetraacetic acid (EDTA), $1 \mathrm{mM}$ phenylmethylsulfonyl fluoride (PMSF) and Complete, EDTA-free (Roche Applied Science, Penzberg, Germany). The homogenized samples were centrifuged twice for 15 minutes at 12,000 $\times \mathrm{g}$ at $4^{\circ} \mathrm{C}$, and aliquots were analyzed for total protein concentration by the Bradford assay using bovine serum albumin as the standard. Next, 10\% glycerol, $0.005 \%$ bromophenol blue, and 5\% $\beta$-mercaptoethanol were added to the supernatants, which were frozen until use. After correcting for the protein concentration of each sample of lung tissue, SDS-polysacrylamide electrophoresis was performed. Protein extracts at a concentration of 40 $\mu \mathrm{g} /$ lane were denatured by heating at $95^{\circ} \mathrm{C}$ for 4 minutes and separated on 10\% SDS-PAGE gels. Electrophoresis was performed at $20 \mathrm{~mA}$ followed by transfer of proteins to polyvinylidene difluoride (PVDF) membranes (Millipore Corporation, Billerica, MA, USA). The transferred membranes were blocked with 5\% skim milk in phosphate-buffered saline (PBS) solution (0.01 M PBS, $\mathrm{pH}$ 7.2 ) at room temperature for 1 hour and then probed with the polyclonal rabbit anti-HSP70 antibody (Clone C92F3A-5, StressGen Biotechnologies Corp., Victoria BC, Canada) (1:1000), and anti- $\beta$-actin antibody (SigmaAldrich, St Louis, MO, USA), diluted in the blocking solution. Membranes were subsequently rinsed three times in TBST solution (0.02 M Tris Base-pH 7.5, 0.5 M sodium chloride, and $0.1 \%$ Tween 20) for 10 minutes and exposed to the secondary HRP-conjugated anti-rabbit IgG for anti-HSP70 antibody for 1 hour at room temperature. Bound antibodies were detected with Super Signal ${ }^{\circledast}$ (Pierce, Rockford, IL, USA). The blots were photographed with a CCD digital scan camera (Cool Saver, Rise \& ATTO Corporation, Japan). The amount of protein on the immunoblots was quantified by image software (CS Analyzer, Rise \& ATTO Corporation, Japan), and the expression levels were presented as ratios to the level of $\beta$-actin.

\section{Histological evaluation}

On BLM day 14, lung tissue samples from treated mice were collected and fixed for 24 hours in 10\% buffered formalin and then embedded in paraffin [30,31]. Sections (4 $\mu \mathrm{m})$ were stained with hematoxylin-eosin. For the quantitative histological analysis, a numeric scale of fibrosis (Ashcroft score) was used [32]. Five sections of the entire lung stained with hematoxylin-eosin were chosen at random from each animal and more than 30 successive microscopic fields at $\times 100$ magnification were allotted a score from 0 (normal) to 6 (severest) in a blinded fashion. In each animal the degree of cell infiltration and pneumonitis/fibrosis in the microscopic sections of lung was assessed as the mean score for the observed fields.

\section{Hydroxyproline analysis}

The hydroxyproline content of lung tissue was measured to evaluate BLM-induced fibrosis, in which excessive collagen deposition is assumed to be one of the most representative findings [33]. After the excised lung tissue was frozen and dried, its dry weight was measured. The tissue was then hydrolyzed in $6 \mathrm{~N} \mathrm{HCL}$ (10 mg/mL dry weight) at $125^{\circ} \mathrm{C}$ for 18 hours. Using the hydrolysis filtrate as a hydroxyproline sample, staining was performed with Ehrlich's reagent following the Prockop method, and the quantity of hydroxyproline $(\mu \mathrm{g} / \mathrm{mL})$ in the hydrolysis products was determined by measuring absorbance at 570 nm with a Shimadzu UV-1200 spectrophotometer.

\section{Immunohistochemical evaluation of HSP70 expression in vivo}

To evaluate the expression of HSP70 in treated lungs, lung tissue was fixed in cold 4\% paraformaldehyde solution for 6 hours, dehydrated gradually with sucrose over a period of 24 hours, fixed in OCT compound (Tissue-Tek; Miles, Elkhart, IN, USA), and frozen. Frozen lung tissue sections $(4 \mu \mathrm{m})$ were prepared and incubated with blocking serum solution in PBS for 1 hour, followed by incubation with primary rabbit anti-HSP70 antibody $(1: 1000)$ at $4{ }^{\circ} \mathrm{C}$ overnight. Antigen-antibody complexes were detected by an avidin-biotin-peroxidase technique (Vectastain ABC Kit; Vector Laboratories, Burlingame, CA, USA) [34]. Diaminobenzidine (DAB) was used to produce a brown color in the target tissue, and the sections were permanently mounted.

\section{TUNEL staining for tissue apoptosis in vivo}

To assess the degree of lung damage, including apoptosis, in the early phase, TUNEL staining was performed using the In Situ Cell Death Detection Kit, POD (Roche Mannheim, Germany) and serial sections of the lungs collected on BLM days 1 and 3. The number of TUNELpositive cells in the whole area of a mid-sagittal section was counted under $\times 400$ magnification, and expressed per total cells.

\section{Bronchoalveolar lavage}

To collect BAL fluid, the trachea was cannulated, the lungs were lavaged six times with PBS (0.5 mL each time) and 
approximately $2.5 \mathrm{~mL}$ of the instilled fluid was consistently recovered. Total cell numbers were counted with a standard hemocytometer. Cytospins were prepared by cytocentrifugation using a Cytospin 2 (Shandon Inc., Cheshire, UK) at $1,000 \mathrm{rpm}$ for 5 minutes and then smears of BAL cells were stained with May-Gruenwald and Giemsa solutions. Cell differentiation was performed by counting at least 200 cells using standard hemocytologic criteria to classify them as alveolar macrophages/monocytes, neutrophils, eosinophils or lymphocytes.

\section{Chemokine assay}

The concentration of macrophage inflammatory protein (MIP)-2 in BAL fluid was determined by ELISA [35]. All procedures were performed according to the manufacturer's instructions.

\section{Statistical analysis}

The results were analyzed using the Mann-Whitney test for comparison between any two groups, and by nonparametric equivalents of ANOVA for multiple comparisons. $P$ $<0.05$ was considered to indicate statistical significance.

\section{Results}

GGA-induced HSP70 expression in the lungs in vivo

We confirmed the induction of HSP70 by GGA and evaluated the appropriate dose and timing of GGA administration in vivo to induce the maximum expression of HSP70. In the naïve mice, the level of HSP70 protein in the lungs of the control vehicle-administered group was almost the same from 0 to 48 hours, and the level at 24 hours after GGA administration was two-fold greater than that at 0 hours and in the control vehicle-administered group (Fig 1A, B). The level of HSP70 protein at 48 hours,

B

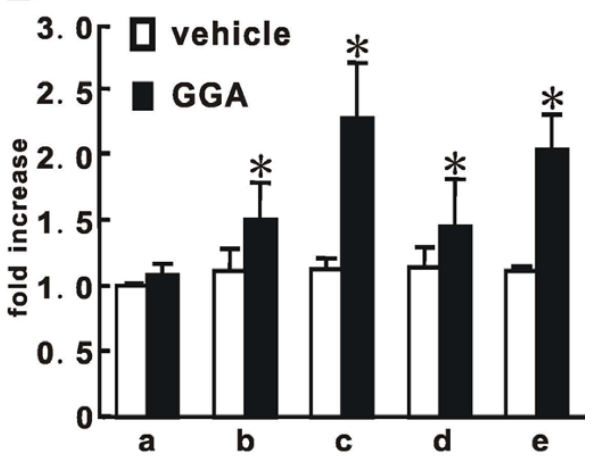

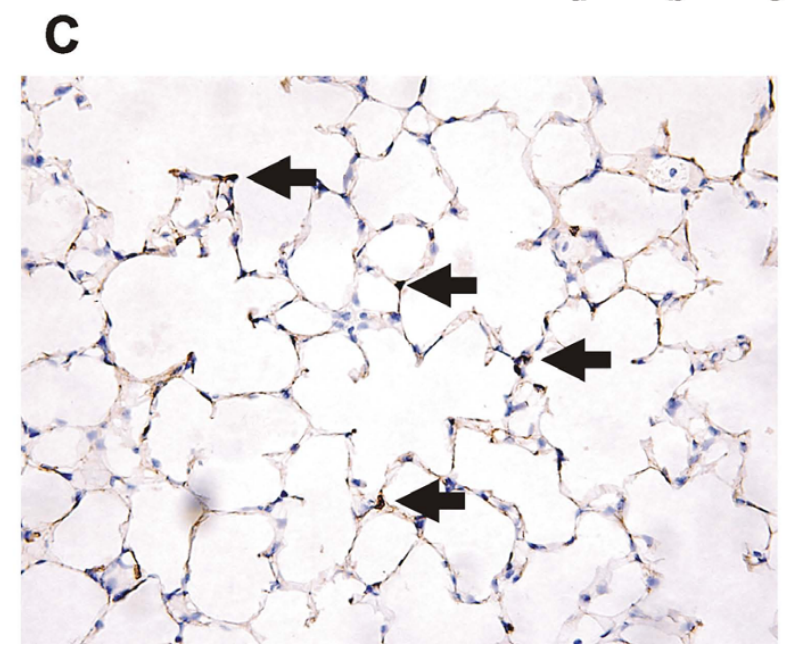

Figure I

GGA-induced expression of heat shock protein 70 (HSP70) in the lungs. (A) Representative immunoblotting data for HSP70 and $\beta$-actin are shown from two similar and independent experiments. The lung tissues from 5 mice at each time were collected. (B) Quantitative results after normalization to the $\beta$-actin signal were summarized. Data shown represent the means \pm SE. a; 0 hour, b; 8 hours, c; 24 hours, d; 48 hours, e; 48 hours, repeated administration of geranylgeranylacetone (GGA) at 24 hours after first administration. *Statistically significant difference $(p<0.05)$ in comparison with the quantitative value of HSP70 level in the lung from mice with vehicle at 0 hours. (C) Representative immunohistochemical staining of HSP70 in GGAtreated mice at 24 hours after GGA administration. Arrows indicate HSP70-positive cells. ( $\times 400$ magnification.) 
after further administration of GGA at 24 hours after first dose, was the same as that at 24 hours (Fig 1A, B: lanes C and e), whereas the level in the lungs at 48 hours after a single dose of GGA was decreased by $25 \%$ from that at 24 hours (Fig 1A, B: lanes c and d). Furthermore, we evaluated the distribution of GGA-induced HSP70 expression in the treated lung by immunohistochemical staining. Immunohistological finding indicated that steady expression of HSP70 in the lungs from GGA-treated mice appeared to be located in alveolar septa (Fig 1-C).

\section{Preventive effect of GGA against BLM-induced lung injury and fibrosis in vivo Monitoring of $B W$}

The GGA-treated mice did not show any change in BW or spontaneous movement, compared with the vehicletreated mice (Fig 2 and data not shown). GGA-treated mice with BLM-induced lung injury (GGA-treated BLM mice) did not show substantial BW loss (1.5\% decrease of BW on BLM day 2) whereas vehicle-treated mice with BLM-induced lung injury (vehicle-treated BLM mice) showed significant loss of BW (8.3\% decrease on BLM day 7) (Fig 2).

\section{Histological evaluation of the lungs}

In comparison with the lungs from vehicle-treated saline mice (inset in Fig 3A), the lungs of vehicle-treated BLM mice revealed severe inflammatory cell infiltration in the subepithelial and subpleural regions with prominent dis-

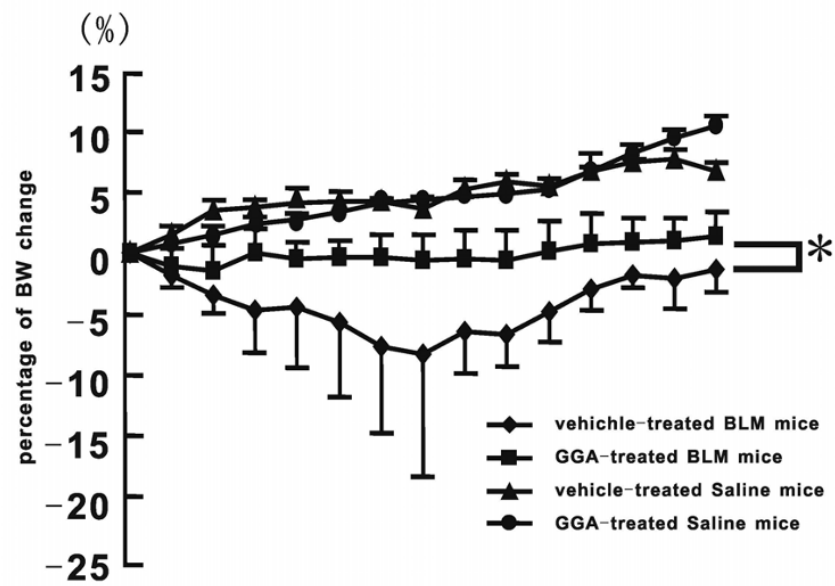

\section{Figure 2}

Monitoring of change in body weight (BW) of BLMtreated mice. Monitoring of change in body weight (BW) of BLM-treated mice at day 0 (GGA-treated mice: $n=5$; GGAtreated BLM mice: $n=10$; vehicle-treated BLM mice: $n=10$ ). Data represent the mean \pm SEM from two independent experiments. Comparison of the BW change in each group was analyzed using nonparametric equivalents of ANOVA. *Statistically significant difference $(p<0.05)$ in comparison. BLM, bleomycin; GGA, geranylgeranylacetone. organized thickening of the alveolar septa, resulting in the loss of normal structure (Fig 3A). GGA-treated BLM mice showed a significant decrease in both interstitial infiltration and airspace cellularity and there were less histological changes, compared with vehicle-treated BLM mice (Fig 3B). Quantitative histological scoring of lung injury showed that the score in the vehicle-treated BLM mice was significantly higher $(3.3 \pm 0.5)$ than that in the GGAtreated BLM mice $(1.7 \pm 0.2)$ (Fig $3 \mathrm{C})$. As the collagen content of the lung, as measured by hydroxyproline content, it was also significantly lower in GGA-treated BLM mice as compared with vehicle-treated BLM mice (vehicletreated BLM mice: $72.5 \pm 18.8 \mu \mathrm{g} / \mathrm{mL}$; GGA-treated BLM mice: $45.3 \pm 3.5 \mu \mathrm{g} / \mathrm{mL}$ ) (Fig 3D).

\section{Cellular characterization and MIP-2 level in BAL fluid}

As previously reported, analysis of the cellular profile in BAL fluid supports the histological findings [32]. The total cell number in the BAL fluid increased significantly in vehicle-treated BLM mice, and was clearly inhibited in GGA-treated BLM mice (vehicle-treated BLM mice: 110.3 $\pm 15.7 \times 10^{4} / \mathrm{mL}$; GGA-treated BLM mice: $39.3 \pm 11.1 \times$ $10^{4} / \mathrm{mL}$ ) (Fig $\left.4 \mathrm{~A}\right)$. GGA treatment significantly suppressed the number of neutrophils in BAL fluid, as well as alveolar macrophages/monocytes (neutrophils: $40.5 \pm 5.4 \times 10^{4}$ / $\mathrm{mL}$ in vehicle-treated BLM mice and $5.2 \pm 3.3 \times 10^{4} / \mathrm{mL}$ in GGA-treated BLM mice) (Fig 4A). MIP-2 levels in BAL fluid from GGA-treated BLM mice were significantly suppressed compared with those from vehicle-treated BLM mice (vehicle-treated BLM mice; $13.0 \pm 2.8 \mathrm{pg} / \mathrm{mL}$, GGAtreated BLM mice; $7.8 \pm 1.6 / \mathrm{mL}$, respectively) (Fig $4-B$ ).

\section{Cytoprotective effect of GGA in BLM-induced lung injury} by TUNEL assay

Until day 3, the histological accumulation of inflammatory cells was still limited and the normal structure of lung remained (Fig 5C, D), but by day 14 large number of inflammatory cells had accumulated and the normal structure was severely damaged in vehicle-treated BLM mice (Fig 3A). As shown in Fig 5, mainly epithelial cells were TUNEL-positive, although some cells beneath the bronchi, most likely inflammatory cells and mesenchymal cells, were also TUNEL-positive. The ratio (\%) of TUNEL-positive cells in the lungs from vehicle-treated BLM mice on BLM days 1 and 3 was significantly larger that those from GGA-treated BLM mice at day 1 and day 3 (BLM day 1: $5.0 \pm 1.9 \%$ in vehicle-treated BLM mice and $2.6 \pm 1.5 \%$ in GGA-treated BLM mice; BLM day 3: $12.3 \pm$ $3.1 \%$ in vehicle-treated BLM mice and $4.7 \pm 1.8 \%$ in GGAtreated BLM mice) (Fig 5C, D).

\section{In vivo GGA-induced HSP70 protein expression in BLM- induced lung injury model}

Western blotting analysis showed that the level of HSP70 protein expression in the lungs from GGA-treated BLM 

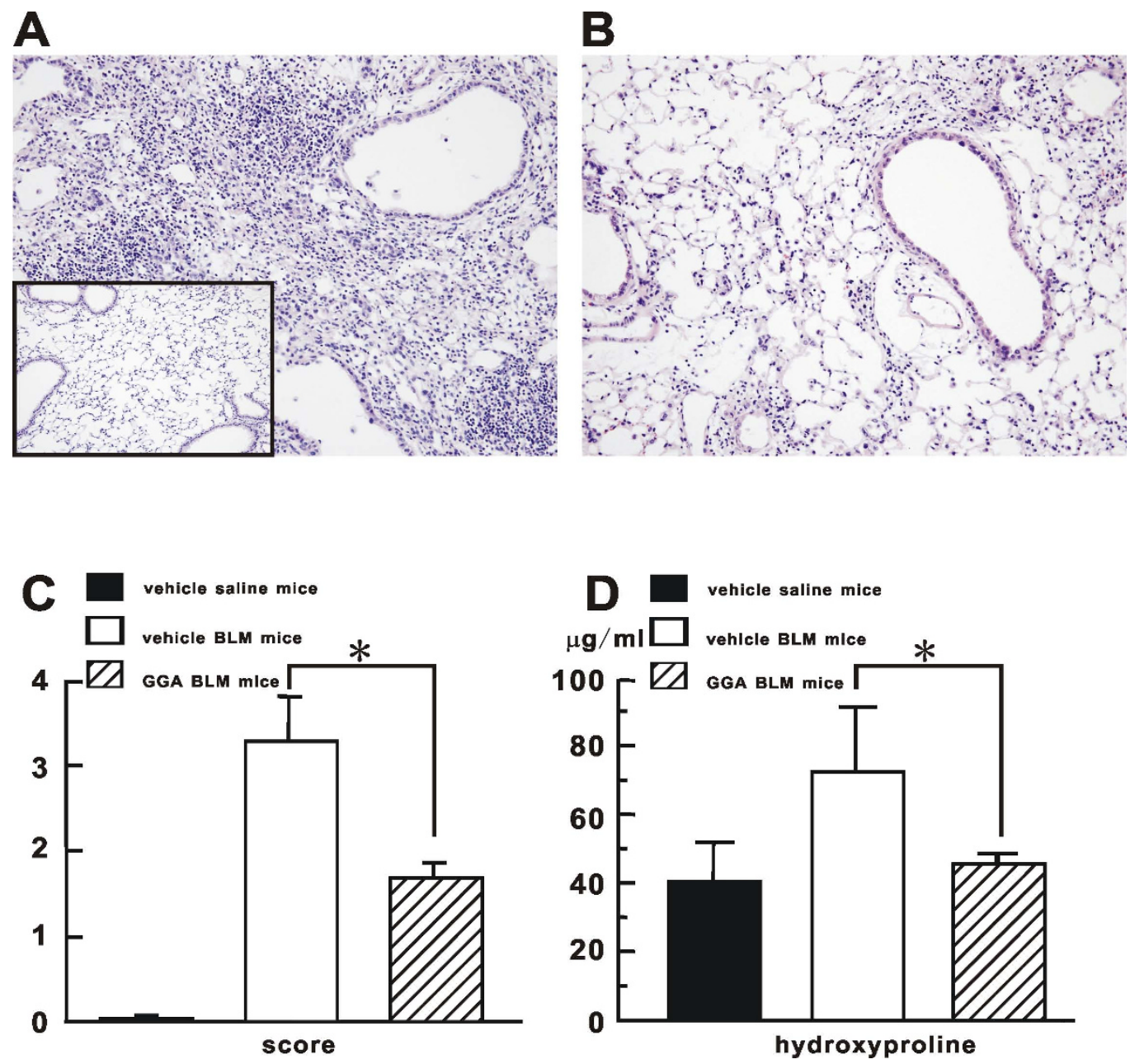

Figure 3

Histological evaluation and measurement of hydroxyproline. Histological evaluation in representative H\&E stained lung sections from vehicle-treated saline mice (Inset in $\mathbf{A})$, vehicle-treated BLM mice (A), and GGA-treated BLM mice (B) on BLM day 14. All images at $\times 400$ magnification. (C) Quantitative scoring of the severity of histological lung fibrosis (Ashcroft score). Data shown represent the mean \pm SEM from two independent experiments using 5 - 10 mice for each group. (D) Hydroxyproline assay performed in the lungs from treated mice on BLM day 14. Each group had at least four mice. Data shown represent the mean \pm SEM from two independent experiments. *Statistically significant difference $(p<0.05)$ in comparison. BLM, bleomycin; GGA, geranylgeranylacetone.

mice on BLM day 3 was significantly greater than in vehicle-treated BLM mice at the same time point (vehicletreated BLM mice: $1.1 \pm 0.1$; GGA-treated BLM mice: $1.9 \pm$ 0.2 ) and that the levels in vehicle-treated saline mice were the same as those in vehicle-treated BLM mice (Fig 6).

\section{Discussion}

We have demonstrated for the first time that repeated oral administration of GGA exerted a protective effect against lung injury in a drug-induced lung injury/fibrosis animal model and subsequently had a suppressive effect on the fibrotic reaction, related to the induction of HSP70, without remarkable adverse events.
While there is no completely satisfactory animal model of IIPs and drug-induced interstitial pneumonitis, the intratracheal BLM-induced lung injury model is relatively wellcharacterized and does exhibit certain features found in the human disease. There are clear limitations to this model in terms of its self-limiting nature, the rapidity of its development and close association with inflammation that accompanies the lung injury $[26,33]$. However, the model is useful for identification of mechanisms and pathogenetic clues that may be relevant to the human disease. Finding such clues may be helpful in providing the basis for human studies to confirm their relevance. 


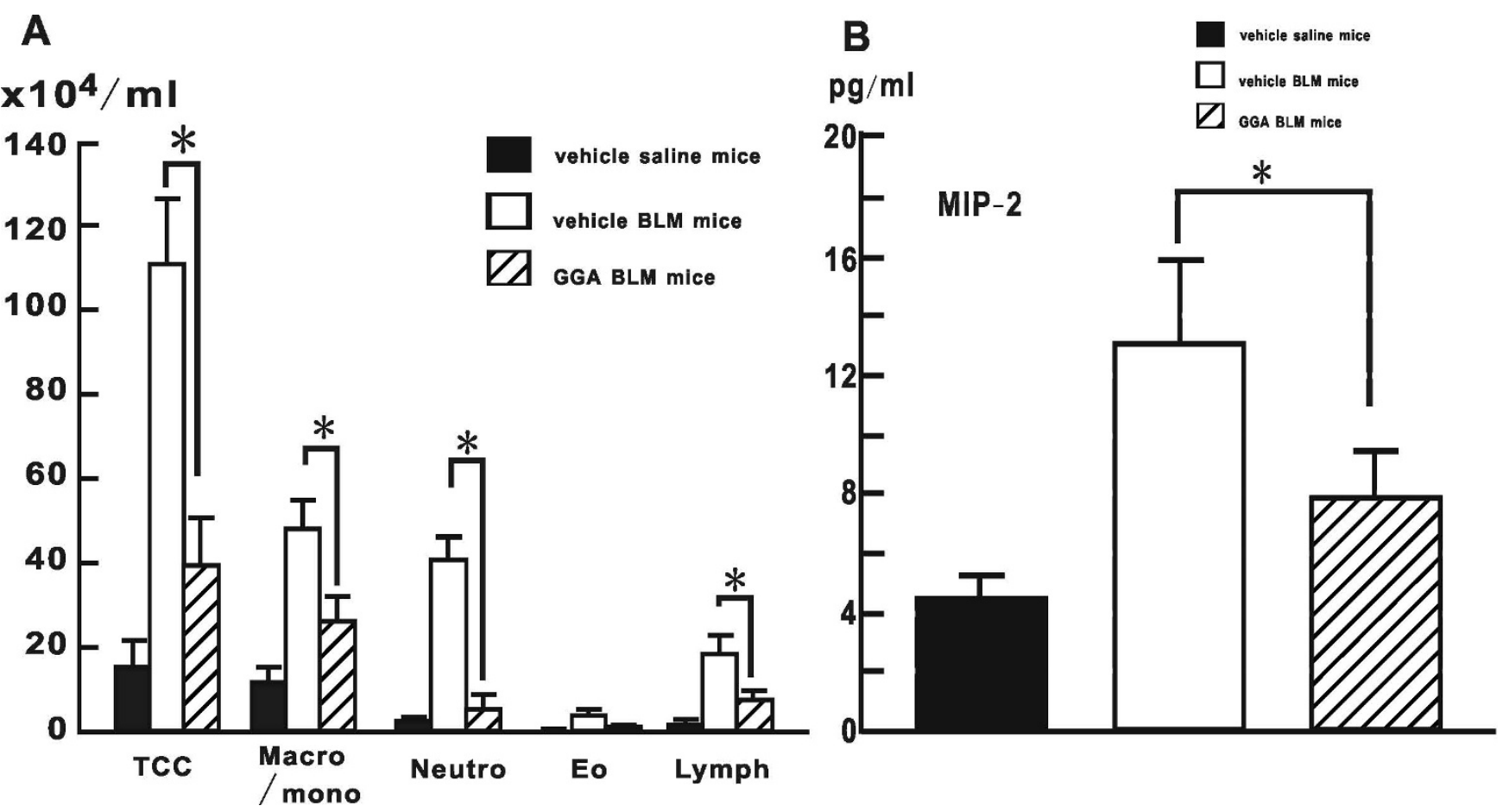

Figure 4

Cellular profiles and macrophage inflammatory protein-2 (MIP-2) level in bronchoalveolar lavage (BAL) fluid. (A) Total cell counts and cell differentiation in BAL fluid from treated mice on BLM day 7. At least four mice were prepared for each group in each experiment. Data shown represent the mean \pm SEM from two independent experiments. TCC: total cell counts; Macro/mono: alveolar macrophages/monocytes; Neutro: neutrophils; Eo: eosinophils; Lym: lymphocytes. (B) MIP-2 levels in BAL fluid from treated mice on BLM day 7 was evaluated by ELISA assay. At least four mice were prepared for each group in each experiment. Data shown represent the mean \pm SEM from two independent experiments. *Statistically significant difference $(p<0.05)$ in comparison.

Our finding that BLM-treated mice lost BW, most likely because of lung injury/fibrosis, was compatible with the change in BW observed in a previous study [27]. Furthermore, we confirmed in detail that BLM induced the following sequential events as follows: apoptosis, accumulation of inflammatory cells, increased chemokine (MIP-2) in BAL fluid, and fibrosis. As it has been accumulated the finding that AECs and endothelial cells injury and death are a critical finding in both IIPs and BLMinduced lung fibrosis model [13,36], apoptosis is assumed to be one of the most important mechanisms, by which fibrotic reaction was mediated. Lung constituents such as AECs and endothelial cells are assumed to be substantial targets in BLM-induced apoptosis in vivo $[13,36]$. Many studies suggest that AEC injury and apoptosis, consistent findings not only in human IPF/UIP but also in BLM-induced lung fibrosis model, might induce initial recruitment of leukocytes, partly because of cytokines and chemokines released from damaged tissues [13,37-40]. In particular, MIP-2 could be the most specific chemokine for the recruitment of neutrophils, by which lung injury might be amplified and developed [28]. Therefore, it has been assumed that intra-tracheal administration of BLM could cause lung injury, partly through the increasing MIP-2 production in the injured lungs, triggered by AEC damage/apoptosis [26].

In our present study, the inflammatory process in the BLM-induced lung injury/fibrosis model was inhibited in the GGA treated-BLM mice, compared with vehicle treated-BLM mice, resulting in the attenuation of the degree of lung fibrosis. These findings were supported by BAL fluid analyses, including inflammatory cell counts and quantification of MIP-2 between GGA treated-BLM mice and vehicle treated-BLM mice. Indeed, the sequential fibrosis was significantly attenuated, assessed by the Ashcroft score and the hydroxyproline content of lung tissue. Although the intra-tracheal BLM induced lung fibrosis model might not be a completely satisfactory animal model for drug-induced lung injury/fibrosis, these findings, in which the preventive effect of GGA against BLMinduced lung fibrosis was successfully shown, could be the clinically helpful clue in providing the basis on the therapeutic strategy for drug-induce lung injury/fibrosis. 


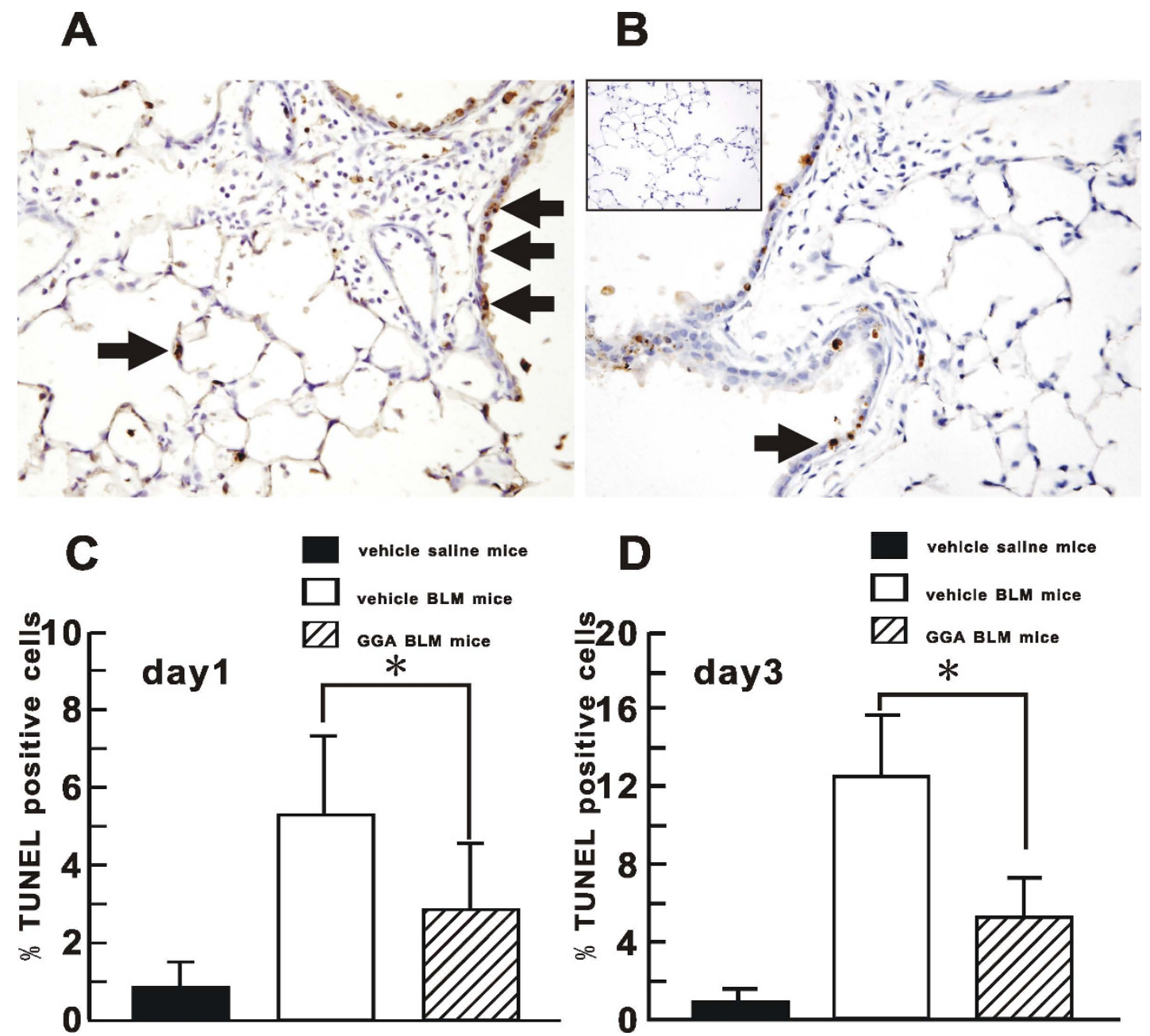

Figure 5

Evaluation of cytoprotective effect of GGA against lung injury by in vivo TUNEL assay. Evaluation of cytoprotective effect of GGA against lung injury by in vivo TUNEL assay of the lungs from treated mice on BLM day I and day 3. Representative lung sections from day3 vehicle-treated BLM mice (A) and GGA-treated BLM mice (B) were shown. TUNEL-positive cells (arrows in $\mathbf{A}$ and $\mathbf{B}$ ) were counted in the whole area of the mid-sagittal section (day I in $\mathbf{C}$ and day 3 in $\mathbf{D}$ ), expressed per total cell counts. At least five mice were prepared for each group in each experiment. Data shown represent the mean \pm SEM from two independent experiments. *Statistically significant difference $(p<0.05)$ in comparison. BLM, bleomycin; GGA, geranylgeranylacetone.

Importantly, oral treatment with GGA did not cause any adverse effects and the mice exhibited normal BW gain and activity during the experiment. GGA treatment significantly ameliorated BW loss in BLM-treated mice during the experiment, suggesting that GGA treatment could exert a general protective effect on damage caused by BLM administration.

Several reports have suggested that protective effect of GGA might be, in part, due to inhibit apoptosis process through induction of HSP70 [25,41-43]. Therefore, we evaluated the expression of HSP70 in vivo to illuminate the possible molecular mechanism, by which administra- tion of GGA could prevent BLM-induced lung injury/ fibrosis in vivo.

Changes in the expression of HSP70 with time after oral administration of $200 \mathrm{mg} / \mathrm{kg}$ of GGA in the rat kidney [25] and heart [41] have been reported. While one study reported that induction of HSP70 at 24 hours after a single oral administration of GGA at $200 \mathrm{mg} / \mathrm{kg}$ was not detected in rat lungs [44], the other report showed the induction of HSP70 in the rat lungs by intra-arterial administration of $1000 \mathrm{mg} / \mathrm{kg}$ of GGA [45]. To our knowledge, there has not been a report demonstrating the induction of HSP70 by oral administration of GGA. In our 


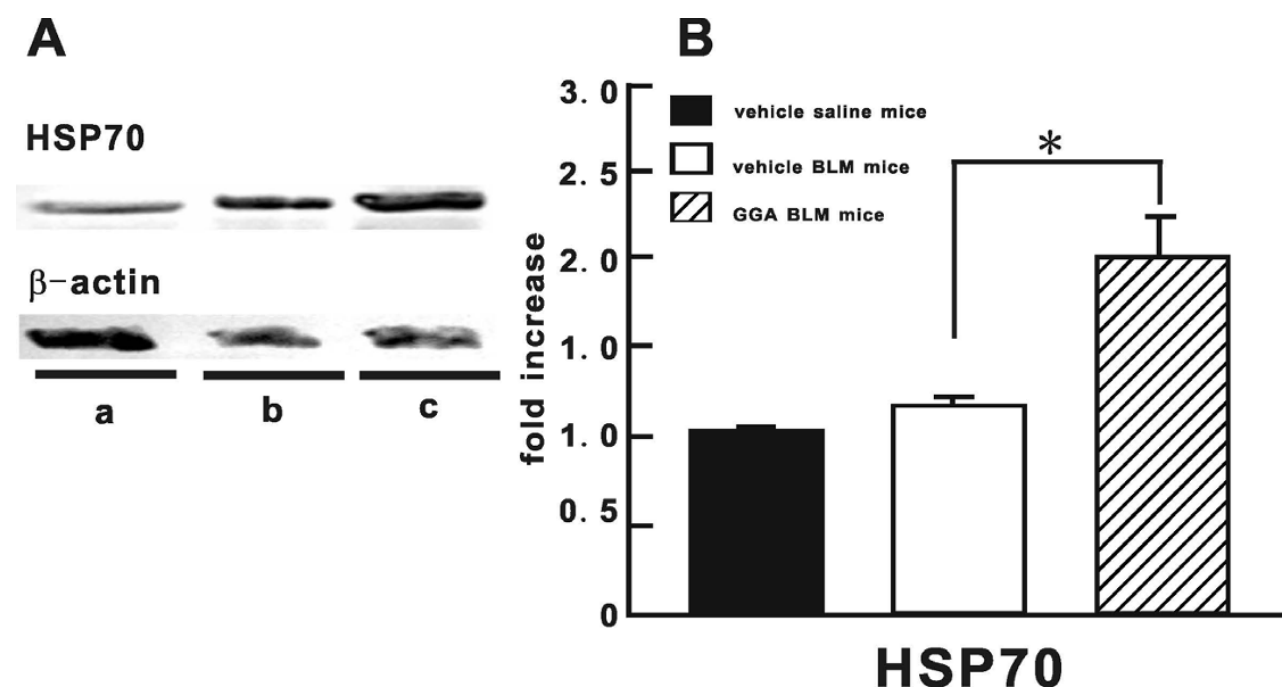

Figure 6

HSP70 protein expression in vivo in BLM-induced lung injury model. (A) Representative immunoblotting data for HSP70 and $\beta$-actin on day 3 from two similar and independent experiments. $\mathbf{a}$; vehicle saline mice, b; vehicle BLM mice, $\mathbf{c}$; GGA BLM mice. (B) Quantitative results of HSP70 after normalization to $\beta$-actin signal were summarized. At least five mice were prepared for each group from two independent experiments. Data shown represent the mean \pm SEM from two independent experiments. *Statistically significant difference $(p<0.05)$ in comparison. BLM, bleomycin; GGA, geranylgeranylacetone; HSP70, heat shock protein 70 .

study, oral administration of GGA at $600 \mathrm{mg} / \mathrm{kg}$ clearly induced increased expression of HSP70 in mouse lungs beginning at 8 hours and reaching maximal levels by 24 hours, in comparison with the faint expression of HSP70 before treatment with GGA, although HSP70 expression at 48 hours after a single dose of GGA reverted back to the same level as at 8 hours. According to these results, sequential and repeated oral-administration of GGA before and after the administration of BLM should be needed to achieve a sufficient protective effect against BLM-induced lung injury and fibrosis.

To determine whether anti-inflammatory effect by GGA in vivo may be due to the anti-apoptosis effect by the attribution of the de novo induction of HSP70 or not, the expression of HSP70 in the treated lungs were performed by western blotting. The slight, but not significant increasing HSP70 expression in the lungs from vehicle treated BLM mice was observed in our present study, compared with those from vehicle treated BLM mice. It is suggested in our present study that the induction of HSP70 by BLM was limited, although it was reported that BLM induced the HSP70 promoter in cultured cells [46] and that the modulation of HSP70 expression by BLM might vary on the cell types such as fibroblasts and alveolar macrophages $[47,48]$. On the other hand, GGA administration induced the significantly increasing expression of HSP70 in BLMtreated lungs, compared with that of BLM-treated lung with vehicle. To evaluate whether GGA treatment can pre- vent the apoptosis in BLM-treated lungs, TUNEL staining was performed for the lungs at BLM day1 and day3. TUNEL staining showed that TUNEL-positive cells were observed mainly in epithelial cells of BLM-treated lungs at day1 and day3. The number of TUNEL-positive cells in the lungs from GGA-treated BLM mice was significantly smaller than those from vehicle-treated mice with vehicle. Furthermore, previous study using quercetin, an inhibitor to the induction of HSPs, showed that quercetin suppressed the expression of HSP70 and abolished the cytoprotective effect of GGA in renal injury model [25]. Taken together with the distribution of steady expression of HSP70 in alveolar septa of the lungs from GGA-treated mice, our findings allow us to speculate that the in vivo induction of HSP70 in this model by pretreatment of GGA might partly protect against BLM-induced cell damage and apoptosis, possibly in AECs, resulting in prevention of sequential inflammation and fibrosis. Although the up-regulation of HSP70 have been shown in human tissue injury [24], the HSP70 expression has not yet been determined in human lung injury. In this study, we focused on the early effect of GGA on HSP70 induction in BLM-induced lung injury and fibrosis model in vivo since it is well assumed that the appropriate control for the initial triggers on lung injury/fibrosis may result in the attenuation of lung injury/fibrosis. Further investigations 1) for the contribution of GGA on HSP70 induction at later phase in this model, 2) for the preventive effect of GGA against the established lung fibrosis, and if so, 3) for 
human lung injury, are warranted. Although it is also well known that both methotrexate and BLM show the cytotoxic effect for lung constituents, resulting in apoptosis $[49,50]$, they are assumed to show different heat shock responses [47]. It might need to be elucidated by further study whether GGA might also protect lung injury due to methotrexate or not.

\section{Conclusion}

In conclusion, our present findings are the first to show that pre-treatment of GGA or GGA-induced derivatives may give us a new strategy to prevent RA patients from interstitial pneumonitis induced by DMARDs after due consideration of both the protocol design in vivo with the higher experimental dose of GGA than the clinical dose and the known limitations of BLM-induced fibrosis.

\section{List of Abbreviations}

AECs: alveolar epithelial cells; ANOVA: analysis of variance; BAL: bronchoalveolar lavage; BLM: bleomycin; BW: body weight; DAB: diaminobenzidine; DMARDs: diseasemodifying anti-rheumatic drugs; EDTA: ethylenediaminetetraacetic acid; ELISA: enzyme-linked immunosorbent assay; GGA: Geranylgeranylacetone; HSP: heat shock protein; IIP: idiopathic interstitial pneumonitis; MIP-2: macrophage inflammatory protein-2; PBS: phosphatebuffered saline; PMSF: phenylmethylsulfonyl fluoride; PVDF: polyvinylidene difluoride; RA: rheumatoid arthritis; SDS: sodium dodecyl sulfate; TUNEL: TdT-mediated dUTP nick and labeling.

\section{Competing interests}

The authors declare that they have no competing interests.

\section{Authors' contributions}

Authors TF and $\mathrm{NH}$ contributed equally to this work. Authors TF, NH, MJ, YH, TK and NI were all involved in the design and implementation of the study including data collection and measurement. Authors TF, NH, MJ, and TK were involved in the analysis and interpretation of the data. All authors read and approved the final manuscript.

\section{References}

I. Ishiguro N, Ito T, Oguchi T, Kojima T, Iwata H, lonescu M, Poole AR: Relationships of matrix metalloproteinases and their inhibitors to cartilage proteoglycan and collagen turnover and inflammation as revealed by analyses of synovial fluids from patients with rheumatoid arthritis. Arthritis Rheum 200I, 44(I I):2503-25II.

2. American College of Rheumatology Subcommittee on Rheumatoid Arthritis Guidelines: Guidelines for the management of rheumatoid arthritis: 2002 Update. Arthritis Rheum 2002, 46(2):328-346.

3. O'Dell JR: Therapeutic strategies for rheumatoid arthritis. $N$ Engl J Med 2004, 350(25):259I-2602.

4. Olsen NJ, Stein CM: New drugs for rheumatoid arthritis. N Engl $J$ Med 2004, 350(2I):2167-2179.
5. Knowles SR, Uetrecht J, Shear $\mathrm{NH}$ : Idiosyncratic drug reactions: the reactive metabolite syndromes. Lancet 2000, 356(924I): I587-|59|.

6. Sugiura F, Kojima T, Oba M, Tsuchiya $\mathrm{H}$, Ishiguro $\mathrm{N}$ : Anaphylactic reaction to infliximab in two rheumatoid arthritis patients who had previously received infliximab and resumed. Mod Rheumatol 2005, I 5(3):201-203.

7. Cooper JA Jr, Zitnik RJ, Matthay RA: Mechanisms of drug-induced pulmonary disease. Annu Rev Med 1988, 39:395-404.

8. Kremer JM, Alarcon GS, Weinblatt ME, Kaymakcian MV, Macaluso M, Cannon GW, Palmer WR, Sundy JS, St Clair EW, Alexander RW, et al.: Clinical, laboratory, radiographic, and histopathologic features of methotrexate-associated lung injury in patients with rheumatoid arthritis: a multicenter study with literature review. Arthritis Rheum 1997, 40(10): I829-1837.

9. Imokawa S, Colby TV, Leslie KO, Helmers RA: Methotrexate pneumonitis: review of the literature and histopathological findings in nine patients. Eur Respir J 2000, I 5(2):373-38I.

10. Camus P, Fanton A, Bonniaud P, Camus C, Foucher P: Interstitial lung disease induced by drugs and radiation. Respiration 2004 , 7 I (4):30I-326.

II. Brown KK: Rheumatoid lung disease. Proc Am Thorac Soc 2007, 4(5):443-448.

12. Kuwano K, Hagimoto N, Maeyama T, Fujita M, Yoshimi M, Inoshima I, Nakashima N, Hamada N, Watanabe K, Hara N: Mitochondriamediated apoptosis of lung epithelial cells in idiopathic interstitial pneumonias. Lab Invest 2002, 82(I 2): I695-I706.

13. Thannickal VJ, Horowitz JC: Evolving concepts of apoptosis in idiopathic pulmonary fibrosis. Proc Am Thorac Soc 2006, 3(4):350-356.

14. Fridlender ZG, Cohen PY, Golan O, Arish N, Wallach-Dayan S, Breuer R: Telomerase activity in bleomycin-induced epithelial cell apoptosis and lung fibrosis. Eur Respir J 2007, 30(2):205-2 I 3.

15. Golan-Gerstl R, Wallach-Dayan SB, Amir G, Breuer R: Epithelial cell apoptosis by fas ligand-positive myofibroblasts in lung fibrosis. Am J Respir Cell Mol Biol 2007, 36(3):270-275.

16. Soti C, Pal C, Papp B, Csermely P: Molecular chaperones as regulatory elements of cellular networks. Curr Opin Cell Biol 2005, I 7(2):2 10-2। 5.

17. Soti C, Nagy E, Giricz Z, Vigh L, Csermely P, Ferdinandy P: Heat shock proteins as emerging therapeutic targets. $\mathrm{Br} J$ Pharmacol 2005, I46(6):769-780.

18. Benjamin IJ, McMillan DR: Stress (heat shock) proteins: molecular chaperones in cardiovascular biology and disease. Circ Res 1998, 83(2): $1 \mid 7-132$.

19. Beere HM, Wolf BB, Cain K, Mosser DD, Mahboubi A, Kuwana T, Tailor P, Morimoto RI, Cohen GM, Green DR: Heat-shock protein 70 inhibits apoptosis by preventing recruitment of procaspase-9 to the Apaf-I apoptosome. Nat Cell Biol 2000, 2(8):469-475.

20. Otaka M, Yamamoto S, Ogasawara K, Takaoka Y, Noguchi S, Miyazaki T, Nakai A, Odashima M, Matsuhashi T, Watanabe S, et al.: The induction mechanism of the molecular chaperone HSP70 in the gastric mucosa by Geranylgeranylacetone (HSPinducer). Biochem Biophys Res Commun 2007, 353(2):399-404.

21. Suemasu S, Tanaka K, Namba T, Ishihara T, Katsu T, Fujimoto M, Adachi H, Sobue G, Takeuchi K, Nakai A, et al:: A Role for HSP70 in Protecting against Indomethacin-induced Gastric Lesions. J Biol Chem 2009, 284(29): I9705-197I5.

22. Hirakawa T, Rokutan K, Nikawa T, Kishi K: Geranylgeranylacetone induces heat shock proteins in cultured guinea pig gastric mucosal cells and rat gastric mucosa. Gastroenterology 1996, I I I (2):345-357.

23. Hagiwara S, Iwasaka H, Matsumoto S, Noguchi T, Yoshioka H: Association between heat stress protein $\mathbf{7 0}$ induction and decreased pulmonary fibrosis in an animal model of acute lung injury. Lung 2007, I 85(5):287-293.

24. Ogawa F, Shimizu K, Hara T, Muroi E, Hasegawa M, Takehara K, Sato $\mathrm{S}$ : Serum levels of heat shock protein 70, a biomarker of cellular stress, are elevated in patients with systemic sclerosis: association with fibrosis and vascular damage. Clin Exp Rheumatol 2008, 26(4):659-662.

25. Suzuki S, Maruyama S, Sato W, Morita Y, Sato F, Miki Y, Kato S, Katsuno $M$, Sobue G, Yuzawa $Y$, et al.: Geranylgeranylacetone ameliorates ischemic acute renal failure via induction of Hsp70. Kidney Int 2005, 67(6):2210-2220. 
26. Huaux F, Liu T, McGarry B, Ullenbruch M, Phan SH: Dual roles of IL-4 in lung injury and fibrosis. J Immunol 2003, I 70(4):2083-2092.

27. Hashimoto $\mathrm{N}$, Jin $\mathrm{H}$, Liu T, Chensue SW, Phan SH: Bone marrowderived progenitor cells in pulmonary fibrosis. J Clin Invest 2004, I I 3(2):243-252.

28. Hashimoto N, Kawabe T, Imaizumi K, Hara T, Okamoto M, Kojima $K$, Shimokata K, Hasegawa $Y$ : CD40 plays a crucial role in lipopolysaccharide-induced acute lung injury. Am J Respir Cell Mol Biol 2004, 30(6):808-8I5

29. Hu B, Wu Z, Jin H, Hashimoto N, Liu T, Phan SH: CCAAT/ enhancer-binding protein beta isoforms and the regulation of alpha-smooth muscle actin gene expression by IL-I beta. J Immunol 2004, I 73(7):466 I-4668.

30. Noguchi M, Imaizumi K, Kawabe T, Wakayama $H$, Horio $Y$, Sekido $Y$, Hara T, Hashimoto N, Takahashi M, Shimokata K, et al.: Induction of antitumor immunity by transduction of CD40 ligand gene and interferon-gamma gene into lung cancer. Cancer Gene Ther 200I, 8(6):42I-429.

31. Jijiwa M, Fukuda T, Kawai K, Nakamura A, Kurokawa K, Murakumo $Y$, Ichihara M, Takahashi M: A targeting mutation of tyrosine 1062 in Ret causes a marked decrease of enteric neurons and renal hypoplasia. Mol Cell Biol 2004, 24( I 8):8026-8036.

32. Aono $Y$, Nishioka $Y$, Inayama M, Ugai M, Kishi J, Uehara H, Izumi K, Sone $S$ : Imatinib as a novel antifibrotic agent in bleomycininduced pulmonary fibrosis in mice. Am J Respir Crit Care Med 2005, I 7 I ( I I): I 279- I 285.

33. Liu T, Jin H, Ullenbruch M, Hu B, Hashimoto N, Moore B, McKenzie A, Lukacs NW, Phan $\mathrm{SH}$ : Regulation of found in inflammatory zone I expression in bleomycin-induced lung fibrosis: role of IL-4/IL-I 3 and mediation via STAT-6. I Immunol 2004, | 73(5):3425-343|.

34. Ishiguro N, Kojima T, Ito T, Saga S, Anma H, Kurokouchi K, Iwahori $\mathrm{Y}$, Iwase $\mathrm{T}$, Iwata $\mathrm{H}$ : Macrophage activation and migration in interface tissue around loosening total hip arthroplasty components. J Biomed Mater Res 1997, 35(3):399-406.

35. Nakanishi T, Imaizumi K, Hasegawa $Y$, Kawabe T, Hashimoto $N$ Okamoto M, Shimokata K: Expression of macrophage-derived chemokine (MDC)/CCL22 in human lung cancer. Cancer Immunol Immunother 2006, 55( I I ): I 320-I 329.

36. Wallach-Dayan SB, Izbicki G, Cohen PY, Gerstl-Golan R, Fine A, Breuer R: Bleomycin initiates apoptosis of lung epithelial cells by ROS but not by Fas/FasL pathway. Am J Physiol Lung Cell Mol Physiol 2006, 290(4):L790-L796.

37. Ware LB, Matthay MA: The acute respiratory distress syndrome. N Engl J Med 2000, 342( I 8): | 334-I349.

38. Tesfaigzi $Y$ : Roles of apoptosis in airway epithelia. Am J Respir Cell Mol Biol 2006, 34(5):537-547.

39. Gross TJ, Hunninghake GW: Idiopathic pulmonary fibrosis. $N$ Engl J Med 200I, 345(7):5 I 7-525.

40. Thannickal VJ, Toews GB, White ES, Lynch JP 3rd, Martinez FJ: Mechanisms of pulmonary fibrosis. Annu Rev Med 2004, 55:395-4I7.

4I. Ooie T, Takahashi N, Saikawa T, Nawata T, Arikawa M, Yamanaka K, Hara M, Shimada T, Sakata T: Single oral dose of geranylgeranylacetone induces heat-shock protein 72 and renders protection against ischemia/reperfusion injury in rat heart. Circulation 200I, I 04(I 5): I 837-I843.

42. Yasuda H, Shichinohe H, Kuroda S, Ishikawa T, Iwasaki Y: Neuroprotective effect of a heat shock protein inducer, geranylgeranylacetone in permanent focal cerebral ischemia. Brain Res 2005, I 032(1-2): I76-182.

43. Yamagami K, Yamamoto $\mathrm{Y}$, Ishikawa $\mathrm{Y}$, Yonezawa K, Toyokuni $\mathrm{S}$, Yamaoka $Y$ : Effects of geranyl-geranyl-acetone administration before heat shock preconditioning for conferring tolerance against ischemia-reperfusion injury in rat livers. J Lab Clin Med 2000, I 35(6):465-475.

44. Nakada J, Matsura T, Okazaki N, Nishida T, Togawa A, Minami Y, Inagaki $Y$, Ito $H$, Yamada $K$, Ishibe $Y$ : Oral administration of geranylgeranylacetone improves survival rate in a rat endotoxin shock model: administration timing and heat shock protein 70 induction. Shock 2005, 24(5):482-487.

45. Tsuruma T, Yagihashi A, Hirata K, Araya J, Katsuramaki T, Tarumi K Yanai $\mathrm{Y}$, Watanabe N: Induction of heat shock protein-70 (hsp70) by intraarterial administration of geranylgeranylacetone. Transplant Proc 2000, 32(7): 1631-1633.
46. Moseley PL, York SJ, York J: Bleomycin induces the hsp $\mathbf{7 0}$ heat shock promoter in cultured cells. Am J Respir Cell Mol Biol 1989, I (2):89-93.

47. Schett G, Redlich K, Xu Q, Bizan P, Groger M, Tohidast-Akrad M, Kiener H, Smolen J, Steiner G: Enhanced expression of heat shock protein 70 (hsp70) and heat shock factor I (HSFI) activation in rheumatoid arthritis synovial tissue. Differential regulation of hsp70 expression and hsf I activation in synovial fibroblasts by proinflammatory cytokines, shear stress, and antiinflammatory drugs. J Clin Invest I998, I 02(2):302-3 I I.

48. Hamilton RF Jr, Li L, Felder TB, Holian A: Bleomycin induces apoptosis in human alveolar macrophages. Am J Physiol 1995, 269(3 Pt I):L318-325.

49. Murakami S, Nagaya N, Itoh T, Kataoka M, Iwase T, Horio T, Miyahara Y, Sakai Y, Kangawa K, Kimura H: Prostacyclin agonist with thromboxane synthase inhibitory activity (ONO-I30I) attenuates bleomycin-induced pulmonary fibrosis in mice. Am J Physiol Lung Cell Mol Physiol 2006, 290(I):L59-65.

50. Raynal S, Nocentini S, Croisy A, Lawrence DA, Jullien P: Transforming growth factor-betal enhances the lethal effects of DNAdamaging agents in a human lung-cancer cell line. Int J Cancer |997, 72(2):356-36|.

\section{Pre-publication history}

The pre-publication history for this paper can be accessed here:

http://www.biomedcentral.com/1471-2466/9/45/prepub
Publish with Biomed Central and every scientist can read your work free of charge

"BioMed Central will be the most significant development for disseminating the results of biomedical research in our lifetime. "

Sir Paul Nurse, Cancer Research UK

Your research papers will be:

- available free of charge to the entire biomedical community

- peer reviewed and published immediately upon acceptance

- cited in PubMed and archived on PubMed Central

- yours - you keep the copyright
BiolMedcentral 